\title{
أثر اختلاف أقمشة الحشو على جودة العروة \\ في صناعة الملابس الجاهزة
}

\author{
أسامة محمد حسين أبوهشيمة لمياء حسن علي حسن \\ المدرسان بقسم الملابس والنسيج المبنه \\ كلية الاقتصاد المنزلي - جامعة حلوان
}

المقدمة والمشكلة:

تمر صناعة الملابس الجاهزة اليوم بمرحلة انتقالية هامة تواجه فيها العديد من التحديات من أجل تحقيق الكفاءة الإنتاجية والنهوض بمسنوى جودة المنتج المحلي ورفع قدرته التتافسية على المستوى المحلي والعالمي • الأمر الذي يحتم على القائمين عليها إتباع منظومة التخطيط الاستراتيجي وتحديد الرؤى البعيدة المدى لئه

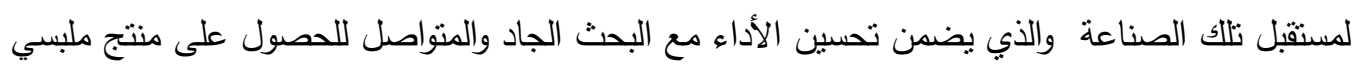
مطابق لمعايير ومقاييس الجودة المتقق عليها دولياً وذلك من خلا المل التأكيد على جودة الخامات الأساسية والمساعدة .

وتعد أقششة الحشو من أهم الخامات المساعدة المستخدمة في صناعة الملابس الجاهزة لما لها من دور

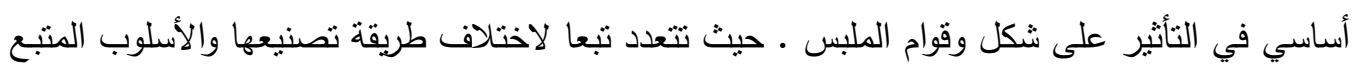

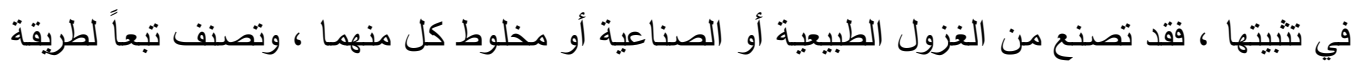

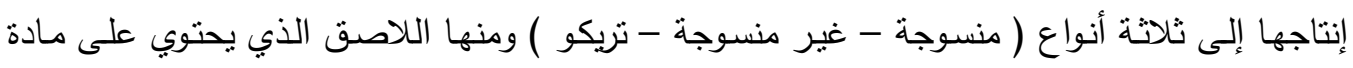

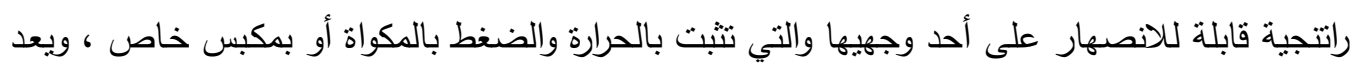
الأكثر شيوعا في صناعة الملابس الجاهزة ، وغير اللاصـق وهو خـالي مـن المـادة اللاصقة القابلـة )

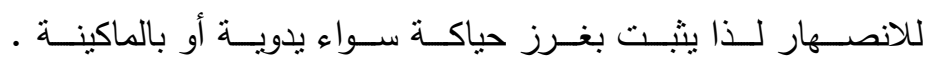

(www.Wikipedia.org

وتقوم صناعة الملابس الجاهزة على أساس عدد من العمليات والمراحل الإنتاجية التي تتبثق منها

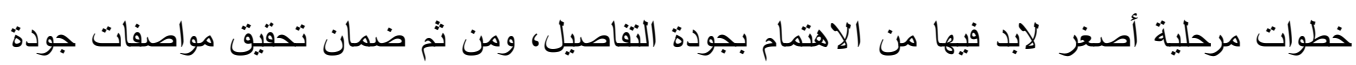
المنتج النهائي.

وتعتبر وسائل الغلق "Closers" عنصراً أساسياً في الملبس ، فعلى الرغم من كونها من التفاصبل

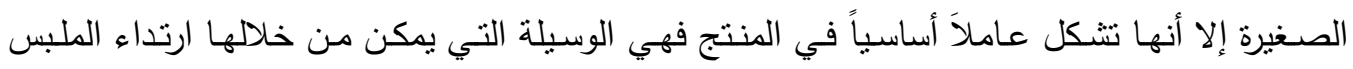


بسـهولة وضبط شكله على الجسم عن طريق غلق فتحاتـه ـ وتتعدد أنواعها وتختلف في مواضـع

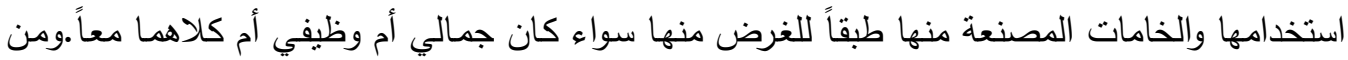

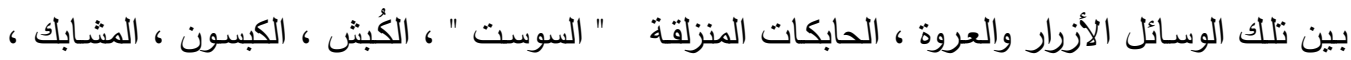

الإبزيمات . (Ruth, E - 235 - 2005

وتُعد عملية تحديد وتتفيذ العروة من الأساسيات الهامة ، حيث تحدد مواضعها مع بداية تصميم المنتج

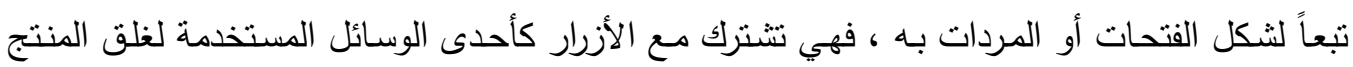

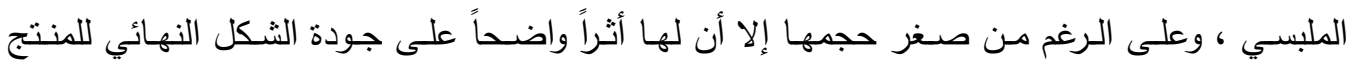

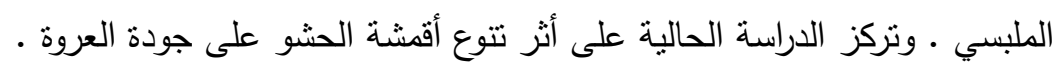
وتصنف العروة لنوعين أساسيين ( عراوي خيط - عراوي قماش ) تتوقف المفاضلة في اختيار أي منهما على نوع المنتج الملبسي والقماش المستخدم وشكل وحجم الأزرار :

\section{Stitch buttonholes أولا العورة الخيط}

وهي تلاك العروة المنتجة من الخيط ، وقد تتفذ بغرز الحياكة اليدوية أو باستخدام ماكينات

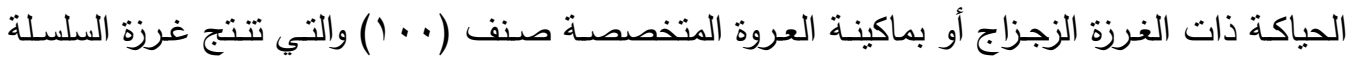
باستخدام خيط علوي واحد، وصنف ( . ـ) والتي تتنج غرزة السلسلة باستخدام خيطين علوي وسفلي

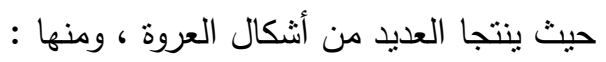

ا- Straight buttonhole العروة المستقيمة والتي تتكون من صفين متوازيين من غرز الزجزاج حيث تبدأ وتتنهي العروة بعدد من الغرز

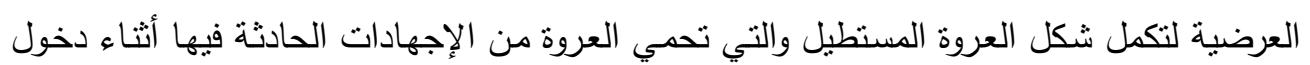

$$
\text { وخروج الأزرار • شكل (1) - (1) }
$$

\section{r- Eyelet buttonhole العروة عينية الشكل}

وهي تللك العروة التي تأخذ شكل العين وتتكون من امتداد خطين مستقيمين منوازيين من الزجزاج

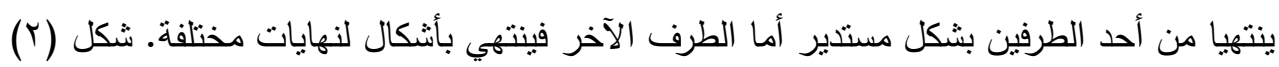
(www.fabriclink.com /textile dictionary )
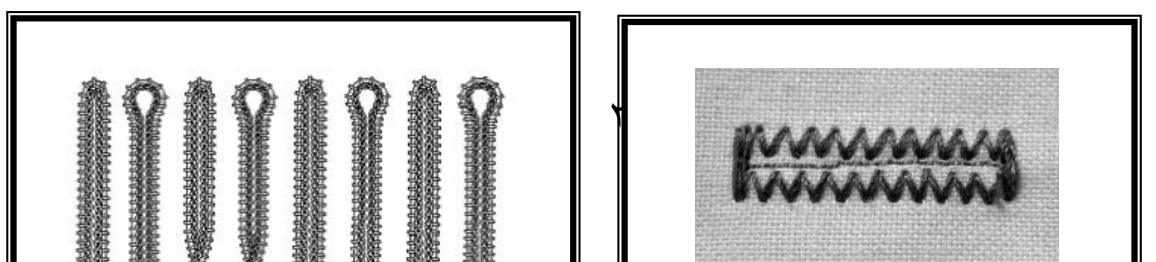


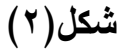

بعض أثكال العروة العينية بنهايات مختلفة

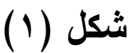

العروة الخيط المستقيمة

r- Round buttonhole : العروة المستديرة

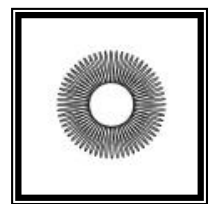

هي عبارة عن عروة دائرية الثكل تستخدم لحفظ الثقوب المنفذة على

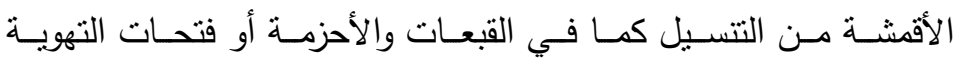

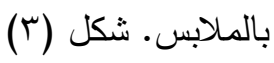

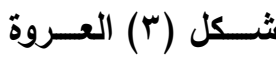

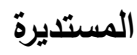

ثانياً العورة القماش Bound button holes

هي تللك العروة المنفذة مـن القماش ، والتـي غالباً مـا تتفذ على الملابس الراقيـة ذات الأقمشـة

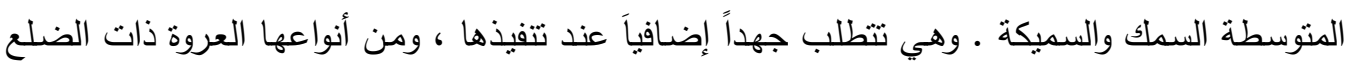

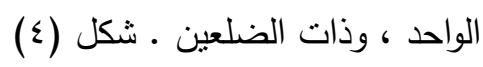

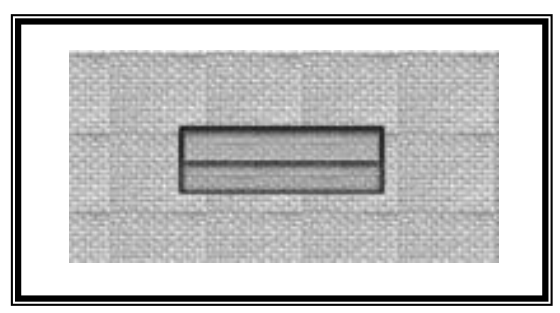




\section{( Colton, v. 1992 - 330)}

\section{شكل (؛ ) العروة القماش ذات الضلعين}

ويحدد مكان واتجاه العروة على المنتج الملبسي طبقاً للتصميم، فقد تأخذ الاتجاه الطولي أو العرضي أو الو المات

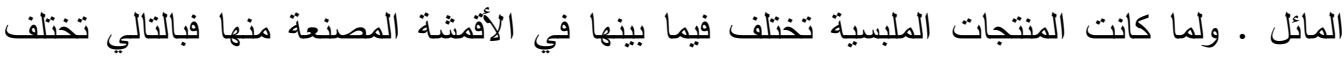

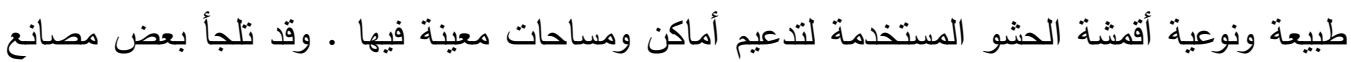

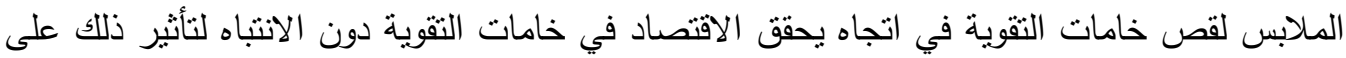

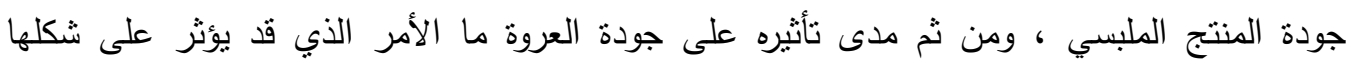

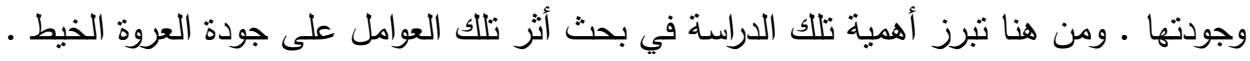

\section{ويمكن تحديد مشكلة البحث في التساؤلات الآتية :}

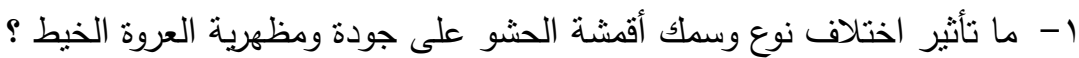
r- ما تأثير اختلاف اتجاه أقمشة الحشو على جودة ومظهرية العروة الخيط ؟ ب- ما تأثير اختلاف اتجاه فتح العروة الخيط على جودة مظهرينها ؟

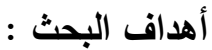
يهذف البحث إلى :

1- التعرف على أثر اختلاف ( نوع قماش الحشو - اتجاه الحشو - سمك الحشو - اتجاه فتح العروة ) على مستوى جودة العروة الخيط في صناعة الملابس الجاهزة . r- الوصول لأفضل المعايير لتحقيق جودة العروة الخبط في صناعة الملابس الجـاهزة وصـولاً بالمنتج النهائي لمستوى الجودة المطلوب.

1- تفيد نتائج هذه الدراسـة في تحقيق متطلبات جودة المنتج الملبسي الكلية من خـلال الاهتمام بجودة التفاصيل الدقيقة . r- تقبد نتائج هذه الدراسة في تحديد أنسب مقومات الجودة المطلوبة في العروة الخيط من خلال تلافي العيوب الفنية أثناء تتفيذها ، وذلك باختيار أنسب المتغيرات.

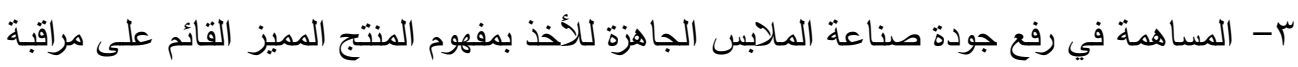
وضمان الجودة في جميع المراحل الإنتاجية . 
أقمشة الحشو Interfacing:

هي طبقة من القماش أو مادة تركييية تضاف بين القماش الأساسي للملبس وقماش البطانة لتكعيم مناطق

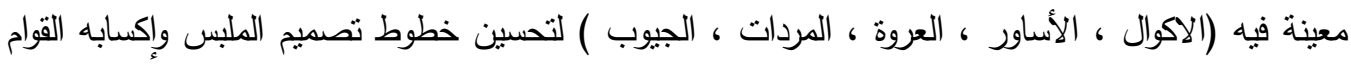

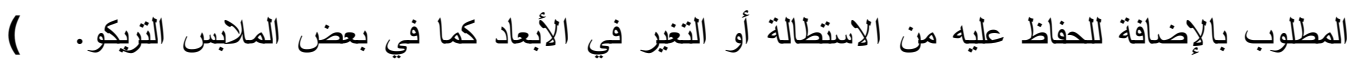
Shoben, M.\& Ward, P. - 1990-56)

\section{الجودة Quality}

الجودة في اللغة تعني : جوّد " والجيد نقيض الرديء" وجاد الثيء جوّده أي صار جبيداً .

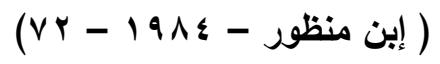

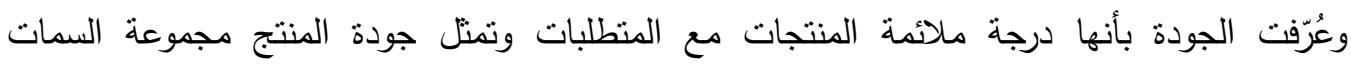
والخصائص التي تحدد مدى ملائمته لتحقيق الغرض الذي أنتج من أجله ليلبى رغبات المستهلك النيات

(Moen, R. \& Nolan, T. - 1991- 42)

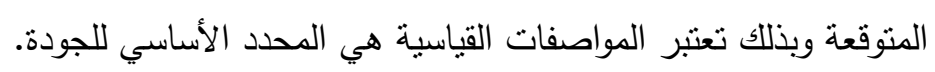

\section{: Buttonholes العروة}

$$
\begin{aligned}
& \text { (مجمع اللغة العربية - ؟199 - 14) } \\
& \text { - العروة من الثوب مدخَلُ زِره }
\end{aligned}
$$

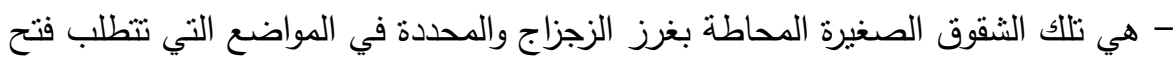
وغلق الملبس باستخدام الأزرار ، وقد تستخدم بشكل زخرفي بألوان ومقاسات مختلفة.

(www.fabriclink.com /textile dictionary )

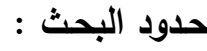

$$
\begin{aligned}
& \text { يقتصر هذا البحث على : }
\end{aligned}
$$

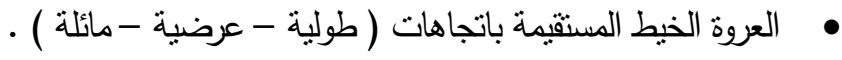

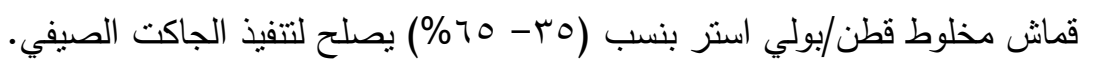

$$
\begin{aligned}
& \text { مأقشة الحشو ( المنسوجة - التزيكو - غير المنسوجة) . }
\end{aligned}
$$

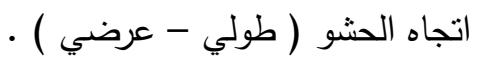

$$
\begin{aligned}
& \text { سمك أقششة الحشو ( متوسط - خفيف ) ) }
\end{aligned}
$$

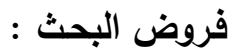


1. يوجد فروق دالة إحصائيا بين متوسطات تقييم جودة العروة طبقاً لنوع الحشو (منسوج - نريكو

$$
\text { - غير منسوج) وسمكه ( متوسط - خفيف ). }
$$

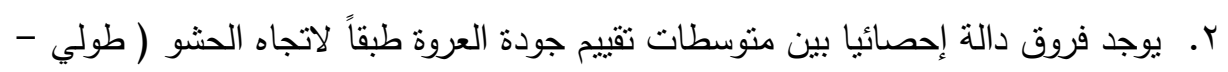

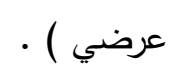

r. يوجد فروق دالة إحصائيا بين متوسطات تقييم جودة العروة طبقاً لاتجاهاتها المختلفة ( طولية

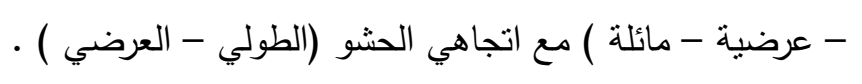

\section{الخطوات الإجرائية :$$
\text { أ- منهج البحث : }
$$

يتبع هذا البحث المنهج التجريبي لملاءمته لتحقيق أهداف الدراسة والتحقق من الفروض.

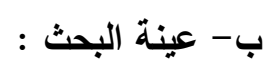

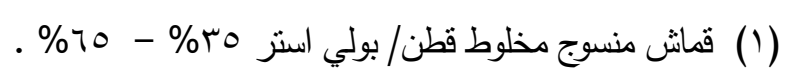

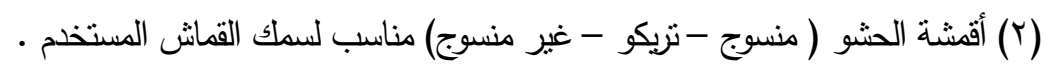

$$
\text { ج- أدوات البحث : (لزيات }
$$

\section{الزيارات الميدانية .}

\section{استمارة لتقييم جودة العروة .}

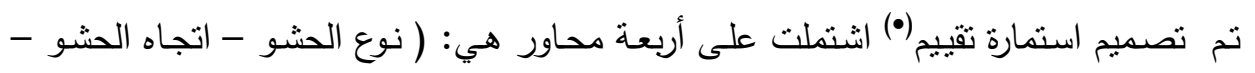

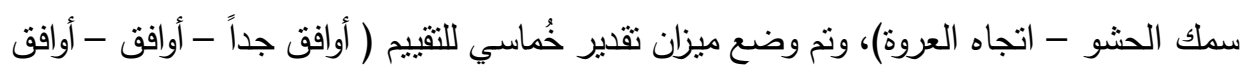

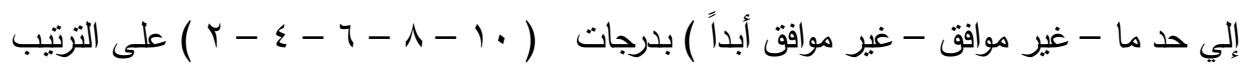

وقد تم التأكد من صدق وثبات أداة البحث كما يلي : 
الصدق : تم حساب صدق الاستمارة عن طريق صدق المحكمين (•)وذلك بعرضها على مجموعة

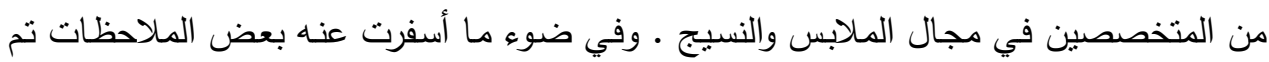
التوصل للصورة النهائية للاستمارة . الثبات : تم حساب ثبات الاستمارة إحصائياً باستخدام معاملي ألفا كرونباخ ، التجزئة النصفية .

\begin{tabular}{|c|c|c|}
\hline \multicolumn{2}{|c|}{ معاملات الثبات } & \multirow{2}{*}{ المحاور } \\
\hline التجزئة النصفية & ألفا كرونباخ & \\
\hline$\cdot, 9 \leq$ & $\cdot, 94$ & المحور الأول \\
\hline$\cdot, \wedge \varepsilon$ & $\cdot, \lambda r$ & المحور الثاني \\
\hline$\cdot, \wedge$. & $\cdot, \vee \vee 9$ & المحور الثالث \\
\hline$\cdot, V \mu$ & $\cdot, V Y$ & الدحور الرابع \\
\hline$\cdot, \wedge 7$ & $\cdot, \wedge \varepsilon$ & المجموع الكلي للدحاور \\
\hline
\end{tabular}

يتضح من الجدول السابق أن معاملات الثبات مرتفعة وتقترب من الواحد الصحيح مما يدل على وجود

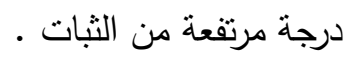

\section{الادراسـات السابقة :}

$$
\text { - دراسة ( ماجدة محمد ماضي - } 991 \text { - (1) ) بعنوان }
$$

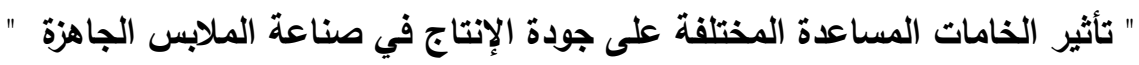

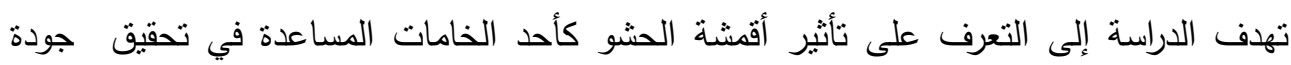
الإنتاج في صناعة الملابس الجاهزة ، والتوصل لحلول لبعض مشكلات الخامات المساعدة لتحقيق

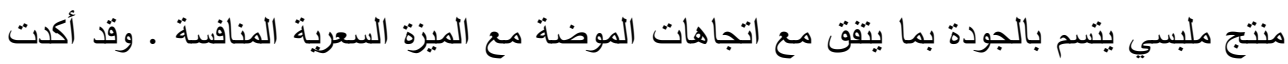

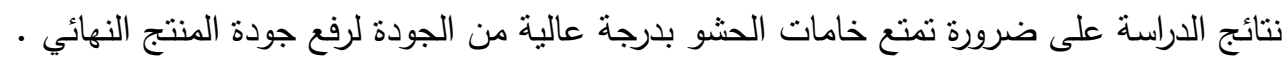

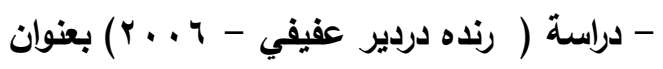

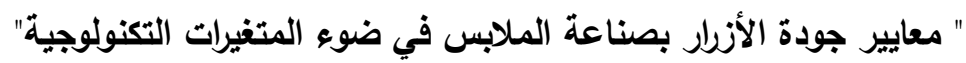


هدفت الدراسة إلى تحديد مدى ملائمة الأزرار للوظيفة ، والتعرف على القواعد والأسس الواجب مراعاتها

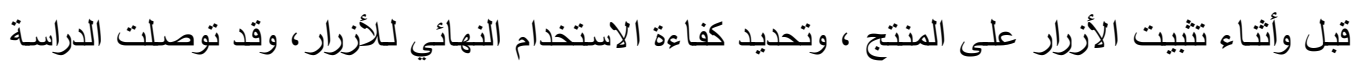

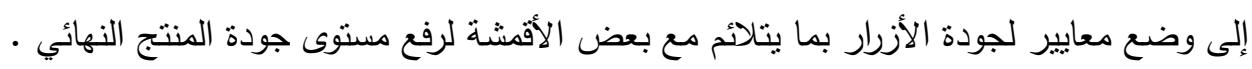

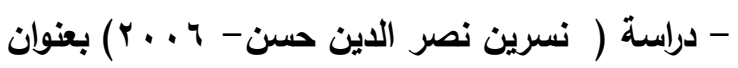

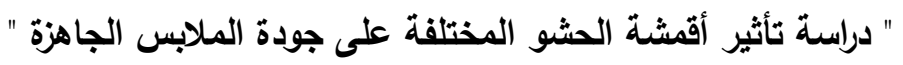

هدفت تلاك الدراسة إلى الحفاظ على انسدال الجاكت الحريمي من خلاد إيجاد علاقة بين خواص القماش الأساسي المستخدم في تنفيذ الجاكت وخواص أقمشة الحشو المستخمة في تدعيمه لإنتاج منتج نهائي خالي من العيوب لتحقيق المنافسة العالمية ـ وكانت أهم النتائج التي توصلت الدراسة وجود علاقات عديدة متباينة بين سمك القماش فئش

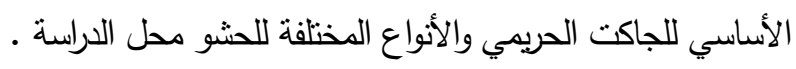

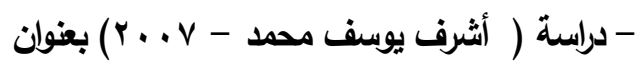

" تكنولوجيا الحشو ومدى تأثيرها على جودة تصميم وإنتاج القميص الرجالي "

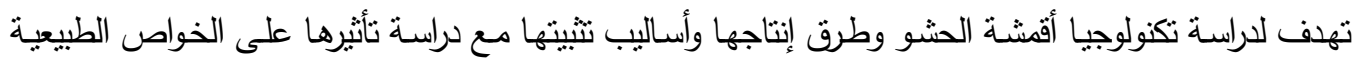

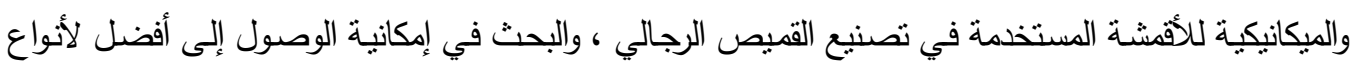

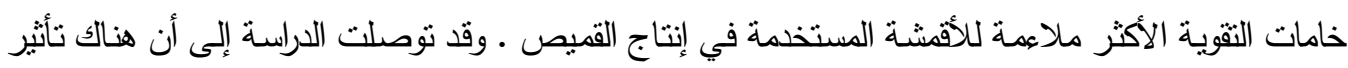

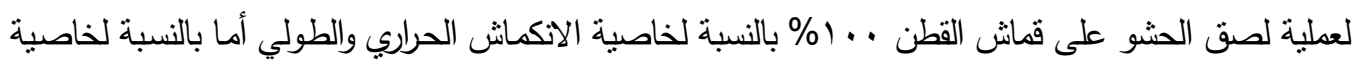

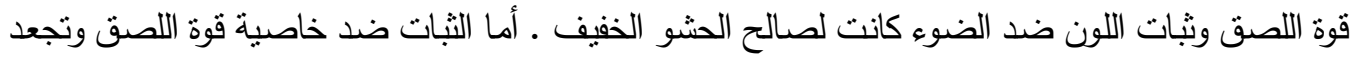
الحياكة فكانت لصالح الحشو المتوسط ـ كما أسفرث النتائج عن وجود علاقة بين نوع الحشو وجميع الخواص السابقة .

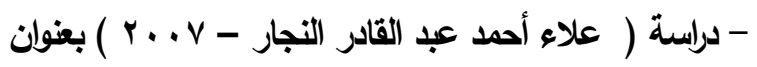

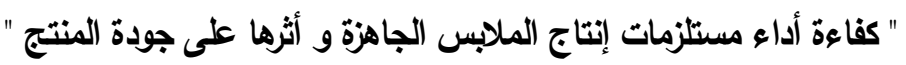

هدفت تلك الدراسة إلى تحديد مدى مطابقة مستلزمات الإنتاج محل الدراسة للمواصفات القياسية العالمية والتعرف

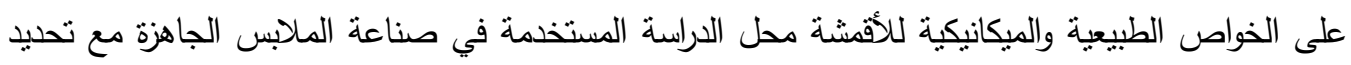

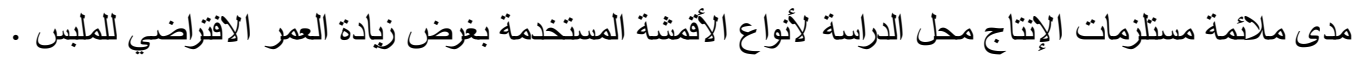

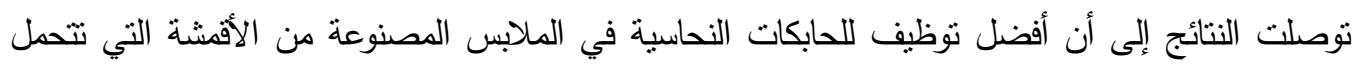

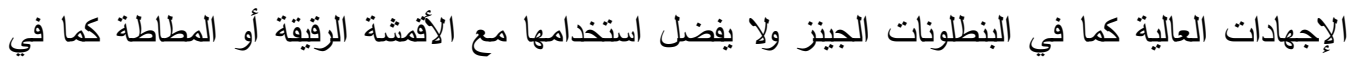
أقششة التريكو أما الحابكات العظمية فأفضل استخدام لها في الملابس الواسعة والتي تحتاج إلي أحمال جانيية

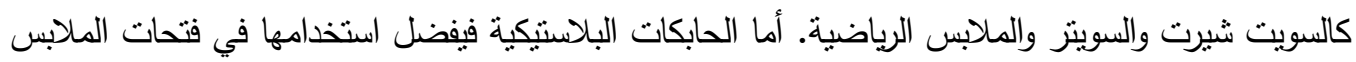

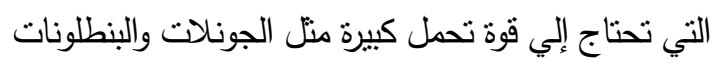


تعقيب على الاراسات السابقة :

يتضح من العرض السابق أن هناك ندرة في الدراسات التي تتاولت العروة بصفة مستقلة إلا أنه بمكن

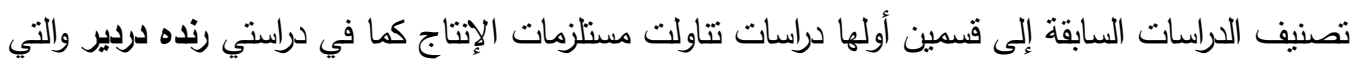

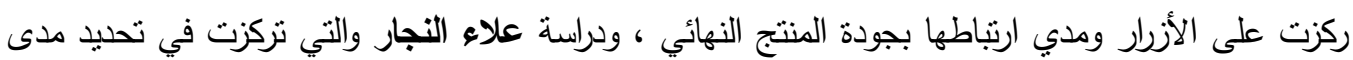

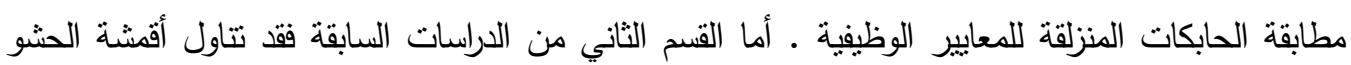

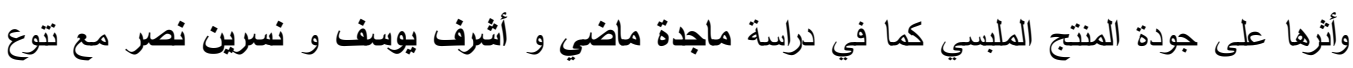

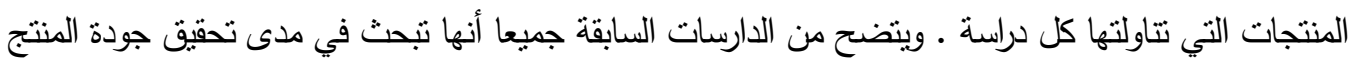
النهائي من خلا استخدام مستلزمات الإنتاج المختلفة وذللك لارتباطها الوثيق بالمظهر الخارجي للمنتج الملبسي

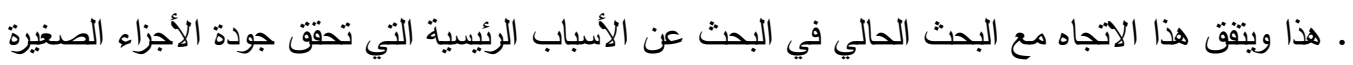
ومدى تأثيرها على الجودة الكلية للمنتج النهائي .

\section{التجارب العملية :}

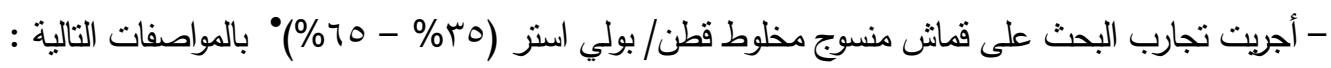

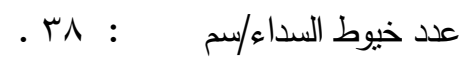

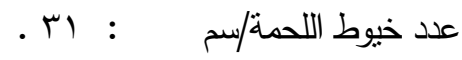

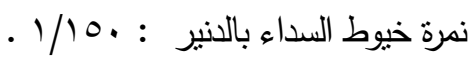

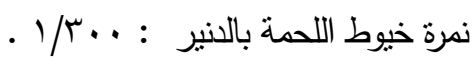

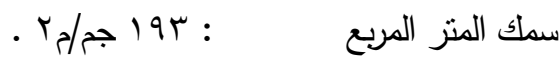

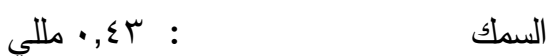

- تم استخدام ستة مسنويات للتنعيم بالحشو طبقا للجدول التالي :

جدول (ץ) مواصفات أقمشة الحشو المستخدمة

\begin{tabular}{|c|c|c|c|c|c|c|}
\hline بالملالي & بالجم / الوزن & علد خيوط & عدال السداء & الرمز & مستوى & الحشو \\
\hline$\cdot, \leqslant \vee$ & 94 & IT & $r$. & $\bar{A}$ & متوسط & \multirow{2}{*}{ منسوج } \\
\hline , ro & TV & 10 & rA & $B$ & خفيف & \\
\hline
\end{tabular}

• تم إجر اء اختبار ات القماش المستخدم طبقاً للمو اصفات المصرية رقم 90 ب لسنة ب79 ا . 


\begin{tabular}{|c|c|c|c|c|c|c|}
\hline •, $\leqslant$ & 90 & IT & IT & C & متوسط & \multirow{2}{*}{ تريكو } \\
\hline or, & or & $1 \varepsilon$ & 11 & D & خفيف & \\
\hline •, KY & To & - & - & $E$ & متوسط & غير \\
\hline$\cdot, 10$ & $r \mu$ & - & - & $F$ & خفيف & منسوج \\
\hline
\end{tabular}

- نم استخدام أقشة الحشو في الاتجاهين الطولي والعرضي •

MODEL

USES

SPEED

Buttonhole width

Buttonhole length

Pressure foot height

Buttonhole shape

Filling system

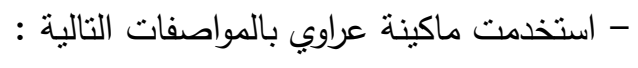

SUN STAR/ SPS/D-BH 3000G

Shirts - Blouses - Dresses -Jackets

4.000 SPM

$6 \mathrm{~mm}$

$40 \mathrm{~mm}$

$13 \mathrm{~mm}$

4 basic

Automatic / manual

- أجريت العروة في ثلاثة اتجاهات ( طولي - عرضي - مائل بزاوية 0؟ ) ). - تم تثيبيت كثافة العروة على المستوى المرتفع والمحدة طبقاً لمواصفات الماكينة .

\section{النتائج والمناقشتة :}

- تم إجراء التحليل الإحصائي لقيم البحث باستخدام برنامج SPSS الإحصائي (الإصدار 0 1) وذلك

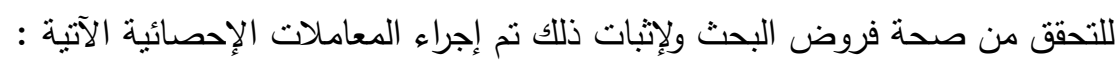

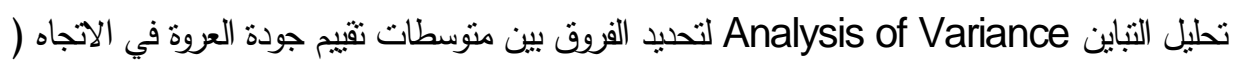

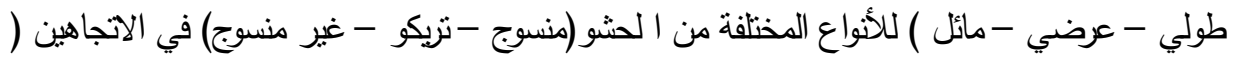

$$
\text { الطولي - العرضي). }
$$

اختبار (ت ) لتحليد دلالة الفروق واتجاهها بين منوسطات نقييم جودة العروة طبقاً لنتغيرات البحث . اختبار ننكن متعدد المدى Duncan's multiple range test لتزتيب معنوية الفروق بين متوسطات المتغيرات المختلفة ، ومعرفة أفضل تثييم لمستوي جودة العروة . 


$$
\text { الفرض الأول : والذي ينص على أنه : }
$$

" يوجد فروق دالة إحصائيا بين متوسطات تقييم جودة العروة طبقاً لنوع الحشو (منسوج - تريكو -

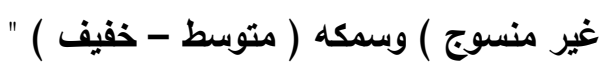

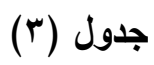

تحليل التباين بين متوسطات تقييم جودة العروة للحشو (منسوج - تريكو - غير منسوج)

\begin{tabular}{|c|c|c|c|c|c|c|}
\hline الدلالة & ف & متوسط المربعات & د & مجموع المربعات & مصدرالتباين & الحشو \\
\hline \multirow{2}{*}{ دال عد } & \multirow[b]{2}{*}{$0, V \wedge 4$} & $0, \vee \vee 0$ & \multirow[b]{2}{*}{100} & $11,0 \leq 9$ & بين المجموعات & \multirow{2}{*}{ S. } \\
\hline & & $\cdot, 991$ & & $10 r, 79$ & المجموعات & \\
\hline \multirow{2}{*}{ غال } & \multirow{2}{*}{$\cdot, Y 7)$} & זחז, & \multirow{2}{*}{100} & • & بين المجموعات & \multirow{2}{*}{ 氶 } \\
\hline & & $1, r \vee q$ & & 190,794 & داخل & \\
\hline
\end{tabular}




\begin{tabular}{|c|c|c|c|c|c|c|}
\hline & & & & & المجموعات & \\
\hline \multirow{2}{*}{ دال عند } & \multirow[b]{2}{*}{$7, \cdots$} & 7,971 & \multirow[b]{2}{*}{100} & $1 \%, q \mu 4$ & بين المجموعات & . \\
\hline & & 1,171 & & IVV,TV & المجموعات & 蛋 \\
\hline
\end{tabular}

يتضح من الجنول السابق أن فيمة (ف) المحسوبة كانت على التزتيب للحشو (منسوج - غير منسوج) هي

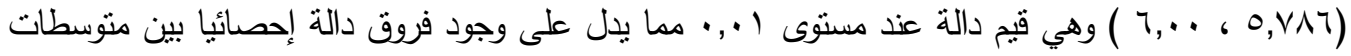

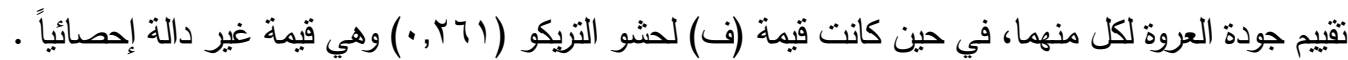

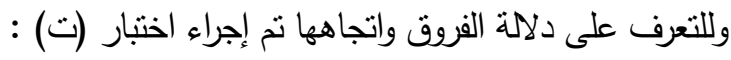

\section{جدول (๕)}

اختبار (ت) لتوضيح دلالة الفروق بين متوسطات تقييم جودة العروة

مع استخدام الحشو المنسوج (المتوسط - الخفيف ) لمونيط

\begin{tabular}{|c|c|c|c|c|c|c|}
\hline واتجاهـالة & د.ح & قيمة & حجم العينة & الانحراف المعياري & المتوسط & سمك \\
\hline \multirow{2}{*}{ دال لصالح } & \multirow{2}{*}{105} & \multirow{2}{*}{$r, Y Y$} & $\vee \wedge$ & r.1, & $V, \wedge T I$ & متوسط \\
\hline & & & $\mathrm{VA}$ & •, qrT & $v, 0 \ldots$ & خفيف \\
\hline
\end{tabular}

يتضح من الجدول السابق أن قيمة (ت) بين جودة تقييم العروة ذات الحشو المنسوج متوسط السمك مع

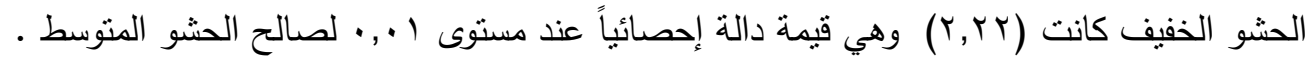

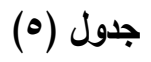

اختبار (ت) لتوضيح دلالة الفروق بين متوسطات تقييم جودة العروة

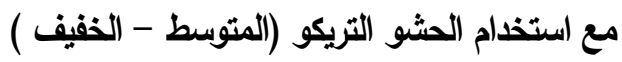

\begin{tabular}{|c|c|c|c|c|c|c|}
\hline واتجالالة & د. & قيمة & العينة & الانحراف & المتوسط & سمك \\
\hline غير دال & $10 \leqslant$ & - & VA & $1,1 \wedge 1$ & $7, \wedge \vee 1$ & متوسط \\
\hline
\end{tabular}




\begin{tabular}{|l|l|l|l|l|l|l|}
\hline & & $\cdot$, YNI & $V \wedge$ & $1, .77$ & $7,9 Y r$ & خفيف \\
\hline
\end{tabular}

يتضح من الجدول السابق أن قيمة (ت) بين جودة ثقييم العروة ذات الحشو التريكو منوسط السمك مع

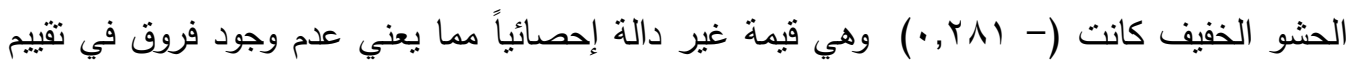

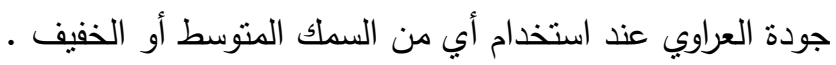

\section{جدول (†) (ال)}

اختبار (ت) لتوضيح دلالة القروق بين متوسطات تقييم جودة العروة

مع استخدام الحشو غير المنسوج (المتوسط - الخفيف )

\begin{tabular}{|c|c|c|c|c|c|c|}
\hline واتجاهها & د. & قيمة & العينة & الانحراف & المتوسط & سمك \\
\hline \multirow{2}{*}{ دال لصالح } & \multirow{2}{*}{$10 \leqslant$} & \multirow{2}{*}{$r, r \leq 0$} & $\vee \wedge$ & שדר, & $\vee, \leqslant \vee \leqslant$ & متوسط \\
\hline & & & VA & $1,1 \vee 9$ & $\checkmark, \wedge ৭ \vee$ & خفيف \\
\hline
\end{tabular}

يتضح من الجدول السابق أن قيمة (ت) بين جودة تقييم العروة ذات الحشو غير المنسوج منوسط السمك

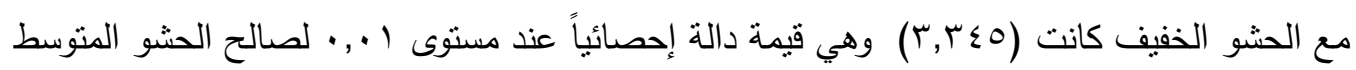
· وبذلك تحقق صحة الفرض الأول.

الفرض الثاني والذي ينص على: - الفي "يوجد فروق دالة إحصائيا بين متوسطات تقييم جودة العروة طبقاً لاتجاه الحشو ( طولي - عرضي )

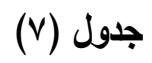

اختبار (ت) لتوضيح دلالة القروق بين متوسطات تقييم جودة العروة

طبقاً لاتجاه للحشو المنسوج لروف لين

\begin{tabular}{|c|c|c|c|c|c|c|}
\hline واتجاهها & ح.د & قيمة & حجم & الانحراف & المتوسط & الحشاه \\
\hline
\end{tabular}




\begin{tabular}{|c|c|c|c|c|c|c|}
\hline دال لصالح & $10<$ & 140 & V^ & מזו, & V, & طولي \\
\hline الطولي & & & Vᄉ & $\cdot, 9 \cdot v$ & $V$, OYo & عرضي \\
\hline
\end{tabular}

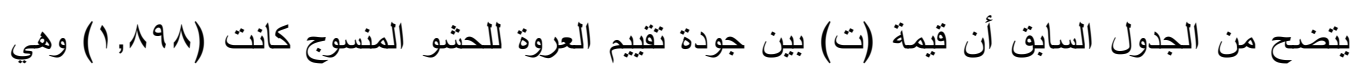
قيمة دالة إحصائياً عند مستوى 0 ., • لصالح الاتجاه الطولي والذي حصل على متوسط تقييم أعلى

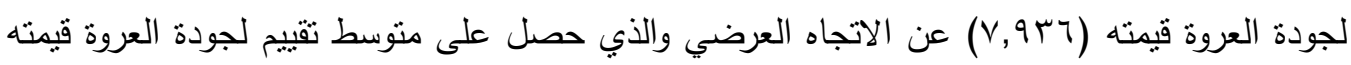

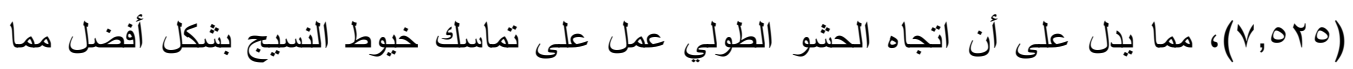
حقه الاتجاه العرضي.

\section{جدول (^)}

اختبار (ت) لتوضيح دلالة الفروق بين متوسطات تقييم جودة العروة

حسب الاتجاه للحشو التريكو

\begin{tabular}{|c|c|c|c|c|c|c|}
\hline واتجاهلة & د.د & قيمة & حجم & الانحراف & المتوسط & الحثاه \\
\hline \multirow{2}{*}{ غير دال } & \multirow{2}{*}{105} & \multirow{2}{*}{$\cdot, r \wedge \varepsilon$} & $\vee \wedge$ & $1, r \cdot \varepsilon$ & T, $9 Y T$ & طولي \\
\hline & & & $\vee \wedge$ & $1, \cdot \leq 9$ & $\neg, \wedge \vee Y$ & عرضي \\
\hline
\end{tabular}

يتضح من الجدول السابق أن قيمة (ت) بين جودة تقييم العروة للحشو التريكو كانت (ع ب, • ) وهي قيمة عير دالة إحصائياً ، حيث كان فارق متوسط تقييم جودة العروة لا يذكر فيما بينهما، ويرجع ذللك إلى درجة المطاطية الموجودة بحلقات التزيكو والتي أدت إلى نشابه النتائج في كلا الاتجاهين الطولي والعرضي.

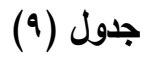

اختبار (ت) لتوضيح دلالة الفروق بين متوسطات تقييم جودة العروة

طبقاً لاتجاه للحشو غير المنسوج

\begin{tabular}{|c|c|c|c|c|c|c|}
\hline الدلالة & د.ح & قيمة & حجم & الانحراف & المتوسط & اتجاه \\
\hline
\end{tabular}




\begin{tabular}{|c|c|c|c|c|c|c|}
\hline واتجاهها & & (ت) & العينة & المعياري & & الحشو \\
\hline \multirow{2}{*}{ غير دال } & \multirow{2}{*}{105} & \multirow{2}{*}{1,777} & $\vee \wedge$ & $1,11 \%$ & שTr, & طولي \\
\hline & & & $\vee \wedge$ & $1, .99$ & $\nu, \cdot r \Lambda$ & ضي \\
\hline
\end{tabular}

يتضح من الجدول السابق أن فيمة (ت) بين جودة تقييم العروة للحشو غير المنسوج كانت (777, 1) وهي قيمة

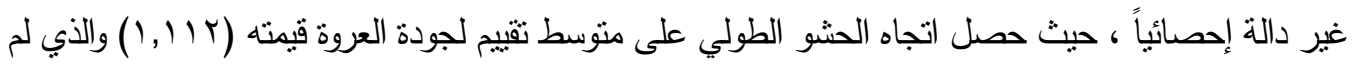
يختلف كثيراً عن ثقييم جودة العروة في الاتجاه العرضي ، مما يدل على أن اتجاهي الحشو غيرالمنسوج الطولي والعرضي لم يختلفا نقربياً في مستوي التقييم. وبذلك يتحقق صحة الفرض الثاني .

الفرض الثالث والذي ينص على:

"يوجد فروق دالة إحصائيا بين متوسطات تقيم جودة العروة طبقاً لاتجاهاتها المختلفة ( طولية -

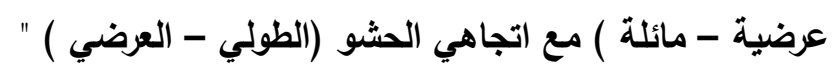

جدول (1.)

تحليل التباين بين متوسطات تقييم جودة العروة في الاتجاه ( طولية - عرضية - مائلة ) للحشو في الاتجاه الطولي

\begin{tabular}{|c|c|c|c|c|c|c|c|}
\hline الدلالة & ف & متوسط المربعاث & $\tau \cdot د$ & المربعاث & مصدرالتباين & التجاه & اتجاه \\
\hline \multirow{2}{*}{ دال عند } & \multirow[b]{2}{*}{$9,0 \leq 7$} & 0,707 & \multirow[b]{2}{*}{$V V$} & 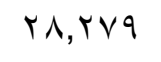 & بين المجموعات & \multirow[b]{2}{*}{ الطولية } & \multirow{6}{*}{ 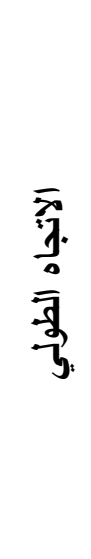 } \\
\hline & & ( & & $\varepsilon r, 7\}$. & المجموعاث & & \\
\hline \multirow[b]{2}{*}{ غير دال } & \multirow[b]{2}{*}{ 1, } & $1,9 Y \wedge$ & \multirow[b]{2}{*}{$V V$} & $9,7 \leqslant 1$ & بين المجموعات & \multirow[b]{2}{*}{ العرضية } & \\
\hline & & $1, \leqslant 1$. & & 1.1,0 & المجموعات & & \\
\hline \multirow{2}{*}{ دال عند } & \multirow{2}{*}{$7, \cdot \Gamma q$} & $v, .09$ & \multirow{2}{*}{$V V$} & ro, r & بين المجموعات & \multirow{2}{*}{ المائلة } & \\
\hline & & 1,179 & & $\Lambda \varepsilon, 10 \leqslant$ & داخل & & \\
\hline
\end{tabular}




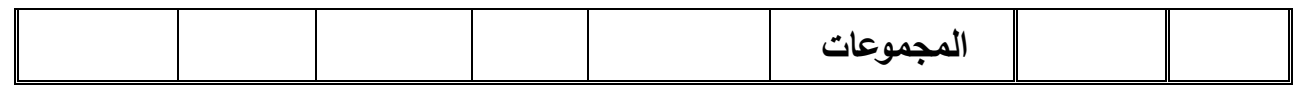

يتضح من الجدول السابق أن قيمة (ف) المحسوبة لمتوسطات نقييم الجودة في الاتجاه الطولي للحثو

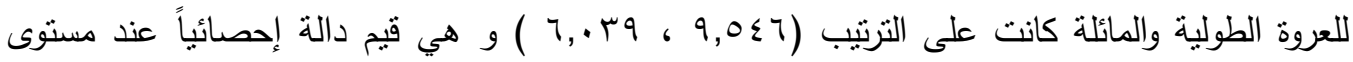
دلالة (1 . , · ) أما قيمة (ف) المحسوبة لمتوسطات تقييم الجودة في نفس الاتجاه للعروة العرضية فكانت

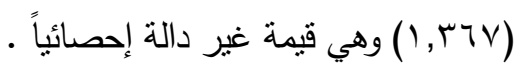

جدول (11)

تحليل التباين بين متوسطات تقييم جودة العروة في الاتجاه ( طولية - عرضية - مائلة ) للحشو في الاتجاه العرضي

\begin{tabular}{|c|c|c|c|c|c|c|c|}
\hline الدلالة & ف & متوبط المربعاث & I & المربعات & مصدرالتباين & التجاه & الحشاه \\
\hline \multirow[b]{2}{*}{ غير دال } & \multirow[b]{2}{*}{$r, \wedge \varepsilon$} & 1,909 & \multirow[b]{2}{*}{$V V$} & $9, \vee 90$ & بين المجموعات & \multirow[b]{2}{*}{ الطولية } & \multirow{6}{*}{ 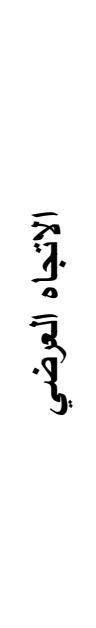 } \\
\hline & & $\cdot, 9 \leq$. & & $7 V, 79 T$ & المجموعات & & \\
\hline \multirow[b]{2}{*}{ غير دال } & \multirow[b]{2}{*}{ r, } & $1,7 \wedge 0$ & \multirow[b]{2}{*}{$V V$} & $\Lambda, \Sigma Y r$ & بين المجموعات & \multirow[b]{2}{*}{ العرضية } & \\
\hline & & $\cdot, \wedge r q$ & & $09,79 r$ & المجموعات & & \\
\hline \multirow{2}{*}{ دال عند } & \multirow[b]{2}{*}{$\varepsilon$, To $_{0}$} & $\varepsilon, \cdot \varepsilon \varepsilon$ & \multirow[b]{2}{*}{$V V$} & $r \cdot, r \mid \wedge$ & بين المجموعات & \multirow[b]{2}{*}{ المائلة } & \\
\hline & & $1, \cdots r$ & & $V Y, 10 \leqslant$ & المجموعات & & \\
\hline
\end{tabular}

يتضح من الجدول السابق أن قيمة (ف) المحسوبة لمتوسطات تقييم الجودة في الاتجاه العرضي للحشو للعروة

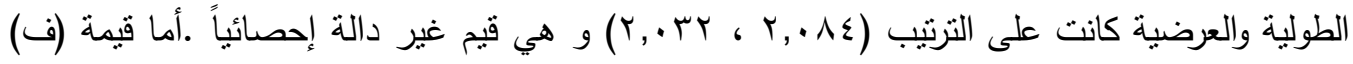
المحسوبة لمتوسطات تقييم الجودة في نفس الاتجاه للعروة المائلة فكانت (0ب .,ع) وهي قيمة دالة إحصائياً عند مستوي (1 (., ) ) 


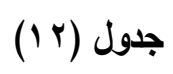

اختبار ننكن تلترتيب متوسطات تقييم جودة العروة في الاتجاهات المختلفة للعروة للحشو في الاتجاه الطولي

\begin{tabular}{|c|c|c|c|c|c|c|c|}
\hline السادستوى & الخامستوى & الالرابع & الثالث & الثاني & الألولتى & سمك الحشو & العروة \\
\hline$F$ & D & C & $E$ & B & A & نوع الحشو & \multirow{2}{*}{\begin{tabular}{ll|}
4 & -3 \\
$: 0$ & 3 \\
$: 0$
\end{tabular}} \\
\hline$V, r \mu$. & $V, r \cdot V$ & $V, \leq 7)$ & $\vee, \wedge \leq \nearrow$ & V,qYT & $9, \cdot 10$ & المتوسط & \\
\hline$C$ & $F$ & B & $E$ & A & D & متوسط & \multirow{2}{*}{ 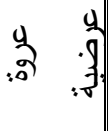 } \\
\hline 7,99 & v & $\vee, r \cdot v$ & $V, 79 Y$ & $\vee, \vee \neg q$ & $\vee, \wedge \leq 7$ & خفيف & \\
\hline C & D & $F$ & E & B & A & متوسط & \multirow{2}{*}{ 岁资 } \\
\hline $0,9 \mathrm{rr}$ & 7 & $\nearrow, \wedge \leq \nearrow$ & $\vee, r \wedge 0$ & $V, \leq 7)$ & V,or & خفيف & \\
\hline
\end{tabular}

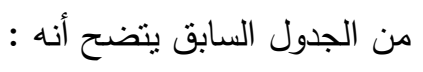

- أفضل تقييم للعروة الطولية للاتجاه الطولي للحشو كان للحشو المنسوج المنوسط السمك وفي المسنوى الأخير للتقييم

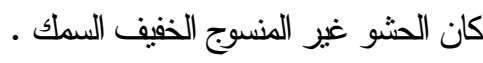
- أفضل تقييم للعروة العرضية للاتجاه الطولي للحشو كان للحشو التزبكو خفيف السمك وفي المسنوى الأخير للتقييم كان التزيكو المتوسط السمك . - أفضل تقييم للعروة المائلة للاتجاه الطولي للحشو كان للحشو المنسوج المتوسط السمك وفي المستوى الأخير للتقبيم كان الحشو التزيكو المتوسط السمك .

\author{
جدول (1T)
}

اختبار ننكن لترتيب متوسطات تقييم جودة العروة في الاتجاهات المختلفة للعروة 


\begin{tabular}{|c|c|c|c|c|c|c|c|}
\hline السادستوى & الخامستوى & الرستوى & المستوى & الثانيتوى & الألولتوى & سمك & الجاه \\
\hline D & $\mathrm{C}$ & $E$ & $\mathrm{~F}$ & B & $A$ & نوع الحشو & \multirow{2}{*}{$\frac{-1}{2}: \frac{-1}{7}$} \\
\hline 7,9r & $V, \cdot V V$ & $V, 710$ & $V, 79 r$ & $\vee, \vee \neg q$ & $\vee, \wedge \leq 7$ & المتوسط & \\
\hline D & $\mathrm{F}$ & C & $E$ & A & B & متوسط & \multirow{2}{*}{ 告 } \\
\hline$\neg, \wedge \leq \varepsilon$ & $\neg, \wedge \leq 7$ & $7,9 Y r$ & $\vee, r \wedge O$ & V,OHA & $V, 710$ & خفيف & \\
\hline $\mathrm{F}$ & $D$ & C & B & $E$ & $A$ & متوسط & \multirow{2}{*}{ 告 } \\
\hline $0, \vee 79$ & 7,710 & $7, \wedge \leq 7$ & $7,9 Y$. & דr,9ז & $V, \leq 7)$ & خفيف & \\
\hline
\end{tabular}

للحشو في الاتجاه العرضي

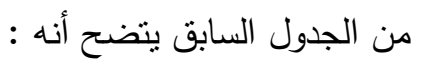

- أفضل تقييم للعروة الطولية للاتجاه العرضي للحشو كان للحشو المنسوج المتوسط السمك وفي المستوى الأخير للتقييم كان الحشو التزيكو الخفيف السمك ـ الخمون - أفضل نقييم للعروة العرضية للاتجاه العرضي للحشو كان للحشو المنسوج خفيف السكك وفي المستوى الأخير اللثقيم

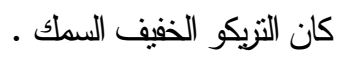
- أفضل تقييم للعروة المائلة للاتجاه العرضي للحشو كان للحشو المنسوج المتوسط السمك وفي المسنوى الأخير اللثقييم كان للحشو غبرالمنسوج الخفيف السمك . وبذلك ينحقق صحة الفرض الثالث.

\section{التوصيات :}

ا. إجراء المزيد من الدراسـات التي تؤكد على الاهتمام بجودة تفاصيل المنتج الملبسي لتحقيق منطلبات المنتج النهائي r. ضرورة الاهتمام بالدراسات التي تتتاول تطبيق مفاهيم ونظم الجودة في جيع المراحل الإنتاجية

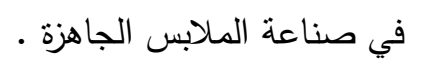
r. فتح المجـال لتطبيـق نتـائج الأبحـاث العلميـة المتميـزة في مجـال صـناعة الملابـس والنسـيج

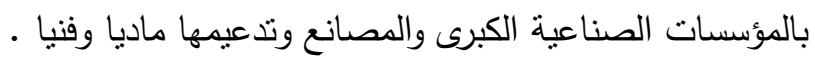

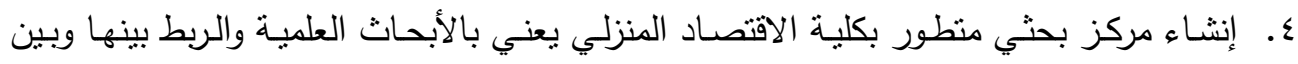

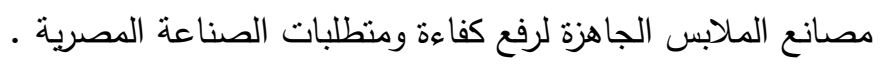


0. إعداد برامج تدريبية متخصصـة ومتطورة في أنظمـة الجودة لتأهيل طـلاب الملابس والنسيج باعنبارهم كوادر فنية متخصصة ومسنقلبية في مجال صناعة الملابس الجاهزة

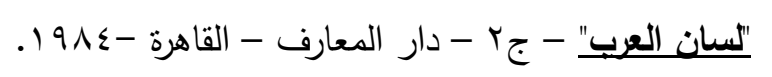

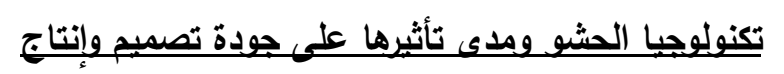

القميص الرجالي - رسالة دكتوراه "غير منشورة" - كلية الاقتصاد

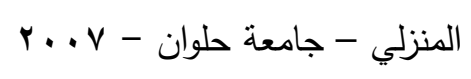

" معاييز جودة الأنبار بصناعة الملابس في ضوان ضوع المتغيرات

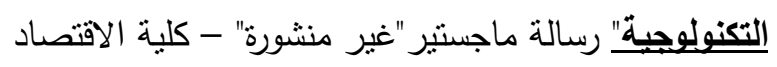

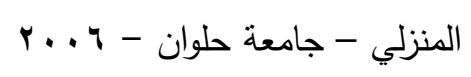

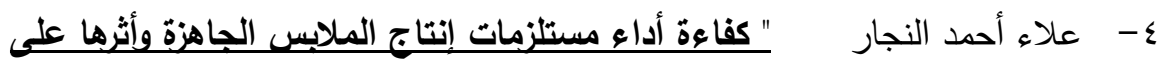

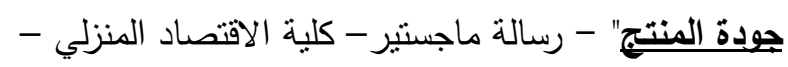

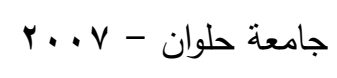

0- ماجدة محمد ماضي " تأثير الخامات المساعدة المختلفة على جودة الإنتاج في صناعة الملابس الجاهزة" ، بحث منشور - مجلة علوم وفنون

$$
\text { دوراسات وبحوث - العدد الرابع - المجلا العانشر - أكتوبر }
$$

7- نسرين نصر الدين "دراسة تأثثر أقمشة الحشو المختلفة على جودة الملابس حسن الجاهزة" - رسالة دكتوراه "غير منشورة" - كلية الفنون التطبيقية

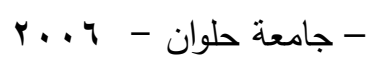

- العيئة المصرية العامة للتوحيد القياسي وجودة الانتاج - المواصفات المصرية القياسية : الطرق القياسية لتقدير طول وعرض وسمك وسمك الأقشة رقم 90 ب- 97 1.

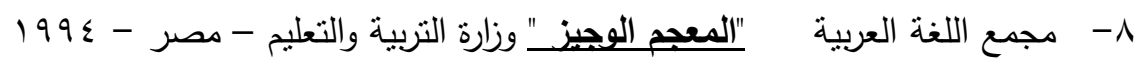

9- Colton, V.

Complete guide to sewing pub. U.S.A., 1992.

10- Moen, R. \& Nolan, T. Improving Quality Through Planned 
Experimentation, 1991

11- Ruth,E.\& Grace, I. Apparel manufacturing sewn product analysis, $4^{\text {th }}$ Edition, Prentice Hall Pub., New Jersey, U.S.A. 2005.

12- Shoben, M\&Ward, P. Pattern cutting and making up for J. outerwear fashion $1^{\text {st. }}$ published, Heinemann, professional Pub.

13- www.ar.wikipedia.org London, 1990.

14- www.fabriclink.com /textile dictionary

\section{ملثص البحث \\ أثثر اختلاف أقمشة الحشو على جودة العروة \\ في صناعة الملابس الجاهزة}

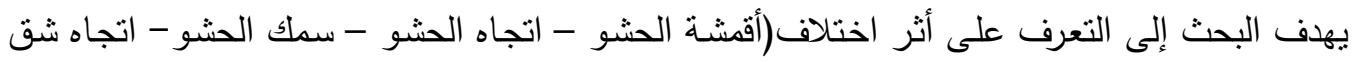

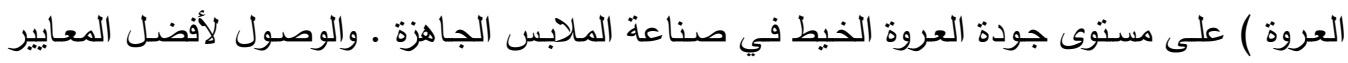

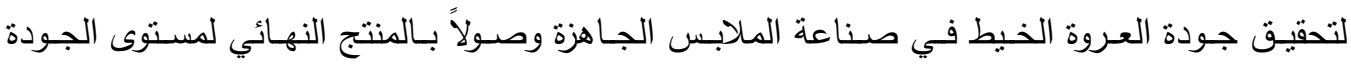

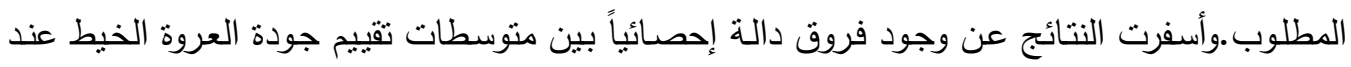

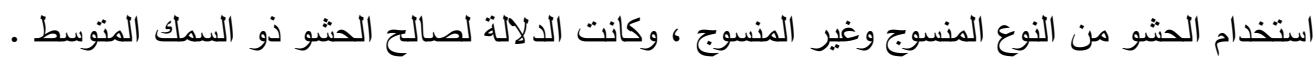

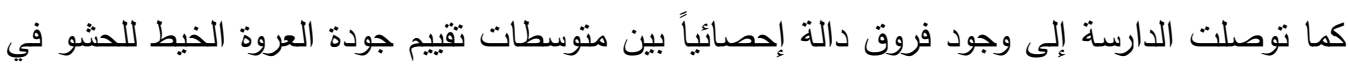

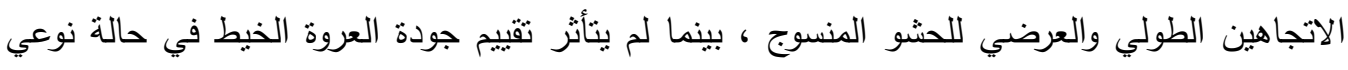

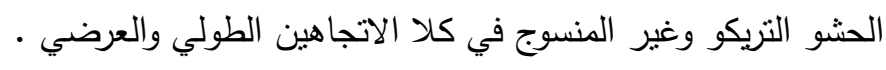

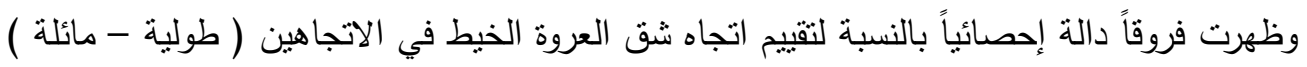

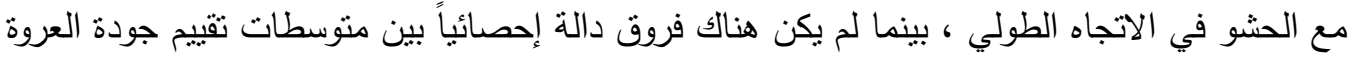

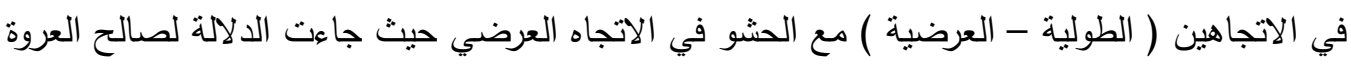

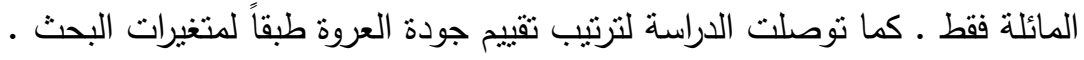

\section{Summary}

The effect of interfacings difference on Buttonhole quality In readymade garment

The research aims to identify the effect of different (type of interfacing and its direction - level of Buttonhole stitches density - Buttonhole 
direction) at the quality level of thread Buttonhole in the ready-made garments, and to access the best standards of quality to achieve the required final product quality. Resulted in findings of the existence of statistical differences between the evaluation averages of thread buttonhole quality when using the woven and non woven interfacings, and the significance for the medium weight interfacing. As the study indicated that there are statistically significant differences between evaluation averages of thread buttonhole quality when using interfacing in both directions, warp and weft of the woven interfacing, while not affected by the assessment of the thread Buttonhole quality evaluation in the case of the knitting and non woven interfacings in both warp and weft directions. Showed statistical differences for a function to evaluate the direction of thread Buttonhole opening in both directions (warp bias) with interfacing in the warp direction, while there was no statistical difference between the averages of buttonhole quality evaluation in both directions (warp - weft) with interfacings in the weft direction where the significant for the diagonal only. The study to indicated to the Buttonhole quality evaluation according to research variables. 